\title{
Analysis of the Probable Signature of Mid-Latitude Electron Density Trough at the Ionospheric Critical Frequencies over Europe
}

\author{
Erdinç Timoçin ${ }^{1,{ }^{\star}}$ İbrahim Ünal ${ }^{2}$ \\ ${ }^{1}$ İnönü University, Faculty of Science and Art, Department of Physics, Malatya, Turkey \\ 2 Inönü University, Faculty of Education, Department of Science Teaching, Turkey
}

\section{Article history}

Received May 29, 2016; accepted March 21, 2017.

Subject classification:

Ionosphere, magnetosphere, critical frequency, mid-latitude electron density trough.

\begin{abstract}
In this study, probable signature of the mid-latitude electron density trough at the ionospheric critical frequencies ( $f_{0} \mathrm{~F} 2$ ) is investigated. For this purpose, hourly ionospheric critical frequencies data obtained from ionosonde stations for the year 1972 are used. These stations are situated between $45^{\circ}-65^{\circ}$ invariant magnetic latitudes $(\Lambda)$ of the Northern hemisphere. The foF 2 data are examined depending on local time $(L T)$, seasons, $\Lambda$ and geomagnetic activity $\left(K_{p}\right)$ variation. The results show that the foF 2 troughs occur in the nighttime hours between dusk and dawn sector for all situations. The troughs under geomagnetic active $\left(\mathrm{K}_{\mathrm{p}}>2^{+}\right)$conditions are more prominent and apparent than that under geomagnetic quiet $\left(K_{p} \leq 2^{+}\right)$conditions. Under geomagnetic active conditions, the troughs and their minimum positions tend to appear at lower $\Lambda$ for four seasons. Also, the average fo 2 values of the trough minimum under geomagnetic active conditions have lower values than that under geomagnetic quiet conditions. It is observed that the seasonal variations have important effects on the structure of the foF2 trough, especially for December Solstice. The results of this study will contribute a better description and prediction of the mid-latitude electron density trough features for the ionospheric F2 peak heights and better understanding the role of the mid-latitude electron density trough on the ionospheric variability.
\end{abstract}

\section{Introduction}

Solar flares and solar wind streams affect the Earth's magnetic field significantly and this interaction causes large and sudden changes in the electron density of the ionosphere. Especially, under geomagnetic active conditions, change in the electron density between $40^{\circ}$ and $70^{\circ} \Lambda$ creates a negative effect on communication and navigation systems. Approximately at $550 \mathrm{~km}$ height, the ambient electron densities trough observed in magnetic mid-latitudes is called mid-latitude electron density trough [Muldrew 1965, Calvert and Van Zandt 1966, Sharp 1966, Carlson 1968,
Rishbeth and Garriott 1969, Tulunay and Sayers 1971, Kelley 1989].

As a result of subsequent studies were performed using electron density data measured by Ariel 3 and Ariel 4 satellites about $550 \mathrm{~km}$ between the years 19601972, the qualitative identification of the mid-latitude electron density trough has been made and the quantitative criteria has been developed [Tulunay and Sayers 1971, Tulunay 1973, Tulunay 1974, Tulunay and Grebowsky 1975b, Tulunay and Grebowsky 1978].

The electron density trough is the ionospheric projection of the magnetospheric plasmapause. The trough marks the region where the electron density variation is abrupt over a narrow range of geomagnetic latitudes. The unpredictable variability greatly limits the efficiency of the operations of communication, radar and navigation systems which employ high frequency (HF) radio waves. The electron density depletion in the trough region reduces the maximum usable frequency that can be reflected by the ionosphere along the great circle. Therefore, it is essential to understand the role of the trough in the ionospheric variability [Tulunay 1973, Grebowsky et al. 1974, Tulunay and Grebowsky 1975a, Tulunay and Grebowsky 1975b, Kersley et al. 1997, Tulunay et al. 1998, Rothkaehl et al. 2000, Tulunay et al. 2003, Pryse et al. 2006, Mikhailov and Leschinskaya 2011].

Earlier studies [Rothkaehl et al. 2000, Tulunay et al. 2003] concluded that (i) It would be advisable to adopt a practical, simple convection model which changes in steps with the planetary geomagnetic activity index $\left(\mathrm{K}_{\mathrm{p}}\right)$ or interplanetary magnetic field (IMF) reversals or any other effective event in order to reflect the influence of the trough phenomena on the ionospheric foF 2 prediction or forecasting algorithms. (ii) Since the foF2 peak can extend above $500 \mathrm{~km}$, the signature of the trough is 
expected to fall in the foF 2 variations all over the world. From this point of view it must be essential to include the influence of the trough in foF2 predictions or forecasts for practical applications and modeling.

To the knowledge of the authors there has been no final model exists which simulates the trough, based on physical principals to be employed for radio communication applications. In practical applications of the HF radio communications in any model that does not include the trough are not a complete model.

The most of previous studies about the mid-latitude electron density trough were performed over the cooperation in scientific and technology-251 (COST-251) area of the Europe. COST-251 is area of the Europe between latitudes of $35^{\circ}-70^{\circ} \mathrm{N}$ and longitude $10^{\circ} \mathrm{W}-60^{\circ} \mathrm{E}$. But these studies were limited to only satellite data and were not exactly investigated effect on the electron densities in the ionospheric F2 peak height of the mid-latitude electron density trough considering seasonal, local time and geomagnetic activity changes by using foF2 data.

The purpose of our study is to investigate possible signature on foF 2 of the structure called the mid-latitude electron density trough depending on local time, seasons, $\Lambda$ and geomagnetic activity changes and is to compare obtained the results from this study with obtained the results from previous studies which were performed for different altitudes. In this way it will establish a better description and prediction of the mid-latitude trough features for foF2. In addition, the results of this work will contribute to better understanding the effect at the ionospheric F2 heights of the mid-latitude electron density trough and the role of the trough on ionospheric variability.

\section{Data and methods of analysis}

In this study, hourly foF2 data of year 1972 are used to investigate probable signature of the mid-la- titude electron density trough at the ionospheric F2 peak heights over the Europe. foF 2 data are obtained from ionosonde stations which are situated between $40^{\circ}$ and $70^{\circ} \Lambda$. The geographic latitudes, geographic longitudes and $\Lambda$ values of these stations are given in the Table 1.

We also used the $\mathrm{K}_{\mathrm{p}}$ index to investigate the effect of geomagnetic activity changes on foF2 values. This data were taken from Space Physics Interactive Data Resource (SPIDR) (http: / / spidr.ngdc.noaa.gov/spidr/).

Data are analyzed depending on seasons, geomagnetic activity and local time as follows:

(1) foF2 data are separated into four seasons as March and September Equinoxes and June and December Solstices.

(2) The hourly $\mathrm{K}_{\mathrm{p}}$ values are calculated from 3-hr $\mathrm{K}_{\mathrm{p}}$ values by using linear interpolation method. Thus, the effect of geomagnetic activity changes on foF2 is investigated more in detail for each local time.

(3) To investigate the geomagnetic activity effect on the foF 2 trough, foF 2 data are separated into two groups as geomagnetic quiet hours and geomagnetic active hours.

(4) Because Ariel satellite returns around the earth about 1344 times during a season, the satellite measures many times electron density for each local time. The average electron density values for each local time are calculated from this data. Then the mid-latitude electron density troughs for each local time are investigated considering variations according to $\Lambda$ of average electron density [Tulunay and Sayers 1971, Tulunay 1973]. Therefore we calculated the average foF 2 values for severally each local time of all seasons and then we investigated variations according to $\Lambda$ of the average foF2 values for different seasons and different geomagnetic activity conditions.

(5). The contours plots of the average foF2 values

\begin{tabular}{|c|c|c|c|c|c|c|c|}
\hline $\begin{array}{l}\text { Station } \\
\text { Names }\end{array}$ & $\begin{array}{l}\text { Geographic } \\
\text { Latitude }\left({ }^{\circ} \mathrm{N}\right)\end{array}$ & $\begin{array}{c}\text { Geographic } \\
\text { Longitude }\left({ }^{\circ} \mathrm{E}\right)\end{array}$ & $\begin{array}{c}\text { Invariant } \\
\text { Magnetic } \\
\text { Latitude } \\
\left({ }^{\circ} \mathrm{N}\right)\end{array}$ & Station Names & $\begin{array}{l}\text { Geographic } \\
\text { Latitude }\left({ }^{\circ} \mathrm{N}\right)\end{array}$ & $\begin{array}{c}\text { Geographic } \\
\text { Longitude }\left({ }^{\circ} \mathrm{E}\right)\end{array}$ & $\begin{array}{c}\text { Invariant } \\
\text { Magnetic } \\
\text { Latitude } \\
\left({ }^{\circ} \mathrm{N}\right)\end{array}$ \\
\hline Bekescsaba & 46.7 & 21.2 & 45.0 & Uppsala & 59.8 & 17.6 & 57.0 \\
\hline Kiev & 50.5 & 30.5 & 48.0 & Lycksele & 64.7 & 18.8 & 61.0 \\
\hline Miedzeszyn & 52.2 & 21.2 & 50.0 & Sodankyla & 67.4 & 26.6 & 64.0 \\
\hline Kaliningrad & 54.7 & 20.6 & 52.0 & Kiruna & 67.8 & 20.4 & 65.0 \\
\hline
\end{tabular}

Table 1. Geographic latitude, geographic longitude and $\Lambda$ values of the ionosonde stations. 


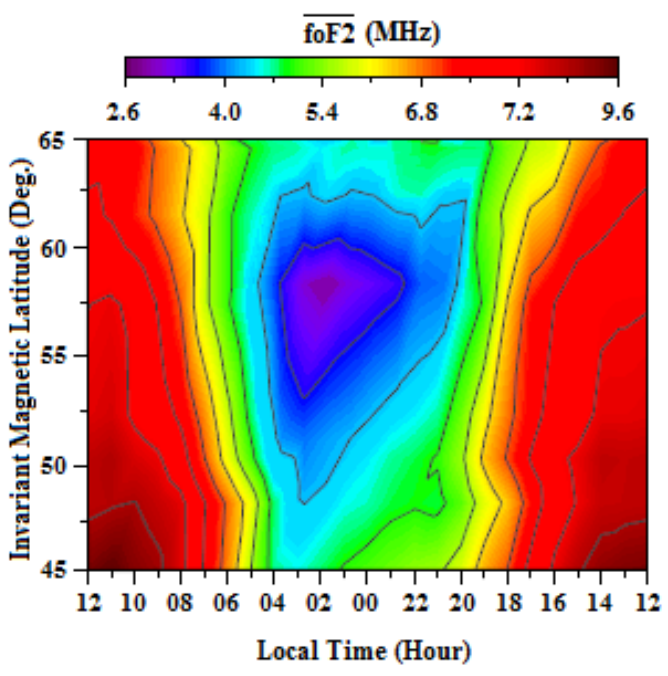

(a)

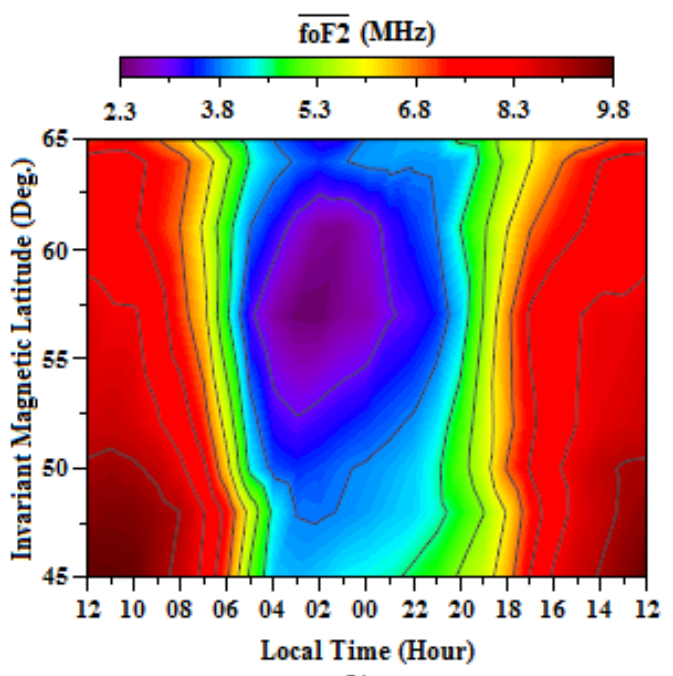

(b)

Figure 1. Variations according to invariant magnetic latitudes of the average foF2 values for different local times during 21 March Equinox period of 1972 year (a) for geomagnetic quiet condition, (b) for geomagnetic active condition.

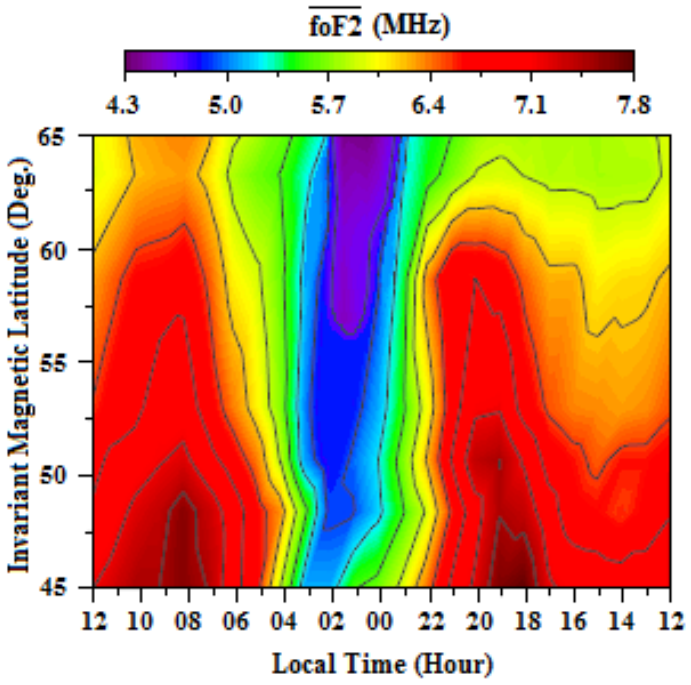

(a)

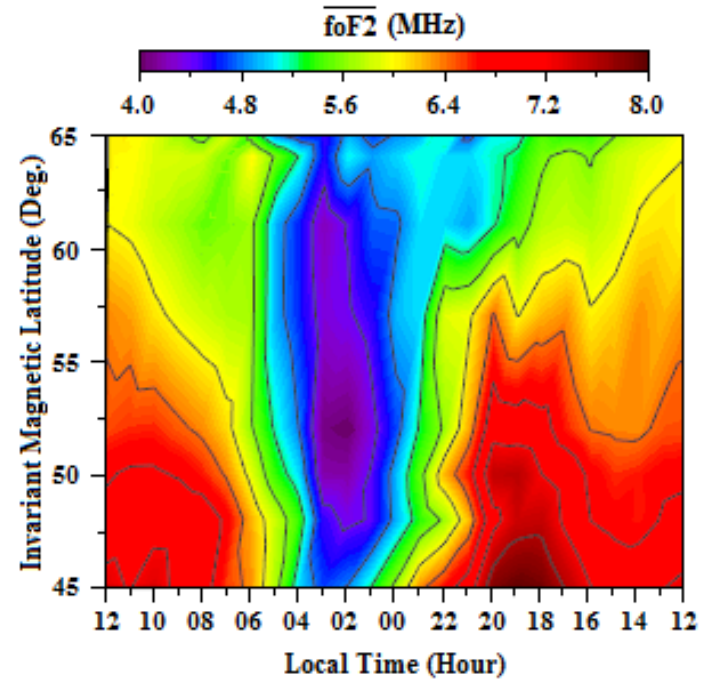

(b)

Figure 2. Variations according to invariant magnetic latitudes of the average foF2 values for different local times during 21 June Solstice period of the year 1972 (a) for geomagnetic quiet condition, (b) for geomagnetic active condition.

are drawn according to $\Lambda$ and local time for different seasons and geomagnetic activity conditions.

\section{Results and discussions}

Figures 1-4 show the variations according to $\Lambda$ of the average foF 2 values for different local times and different geomagnetic active conditions during March and September Equinoxes, and June and December Solstices of the year 1972 .

As seen in Figures 1 and 3, the average foF 2 values during the daytime hours between 05-19 LT gradually decrease with increasing $\Lambda$ under both the geomagnetic quiet and geomagnetic active conditions. The boundaries of this local time region where the average foF 2 values gradually decrease with increasing $\Lambda$ is different for June and December Solstices. The average
foF2 values of local times between 04-00 LT for June Solstice gradually decrease with increasing $\Lambda$, while the average foF 2 values of local times between 0615 LT for December Solstice gradually decrease with increasing $\Lambda$. That is, the effect of the mid-latitude electron density trough on foF 2 is not observed at all of these local times. In addition, as seen in the Figure $2 \mathrm{a}$, the average foF 2 values of local times between 00 04 LT for June Solstice under geomagnetic quite conditions gradually decrease with increasing $\Lambda$ similarly to latitudinal behavior of the average foF 2 values of local times between 04-00 LT. That is, under geomagnetic quiet conditions, the effect of the mid-latitude electron density trough on foF 2 was not exactly observed for any local times of June Solstice.

As seen in the Figures 1a and 3a, the foF 2 troughs 


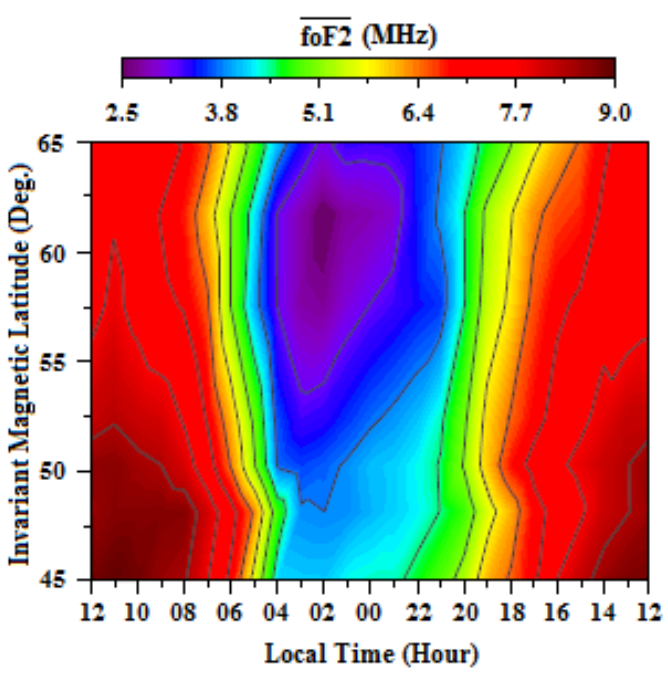

(a)

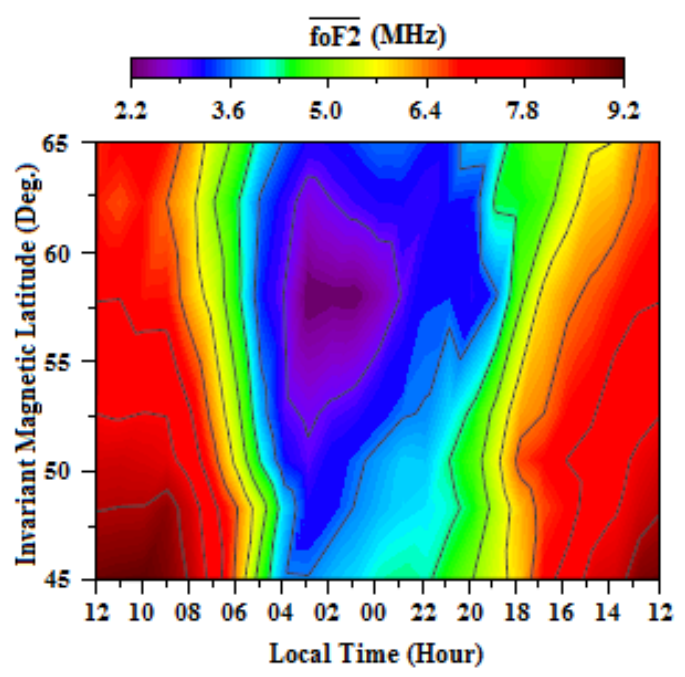

(b)

Figure 3. Variations according to invariant magnetic latitudes of the average foF 2 values for different local times during 23 September Equinox period of the year 1972 (a) for geomagnetic quiet condition, (b) for geomagnetic active condition.

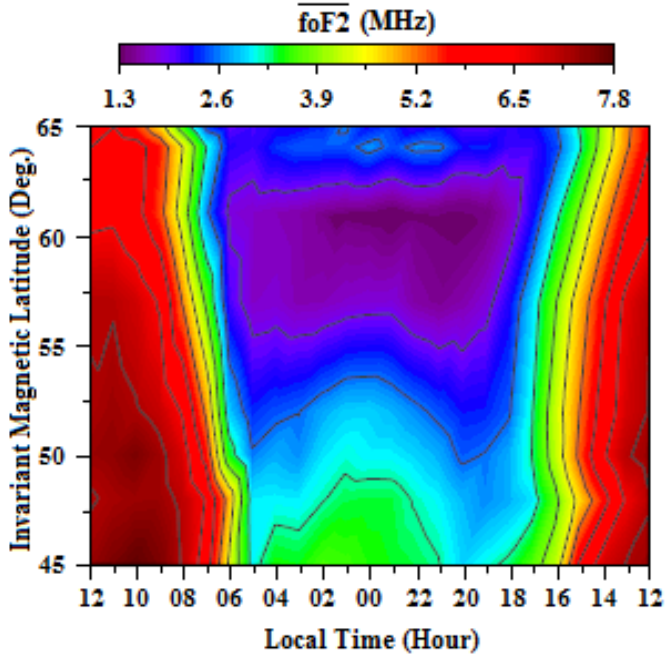

(a)

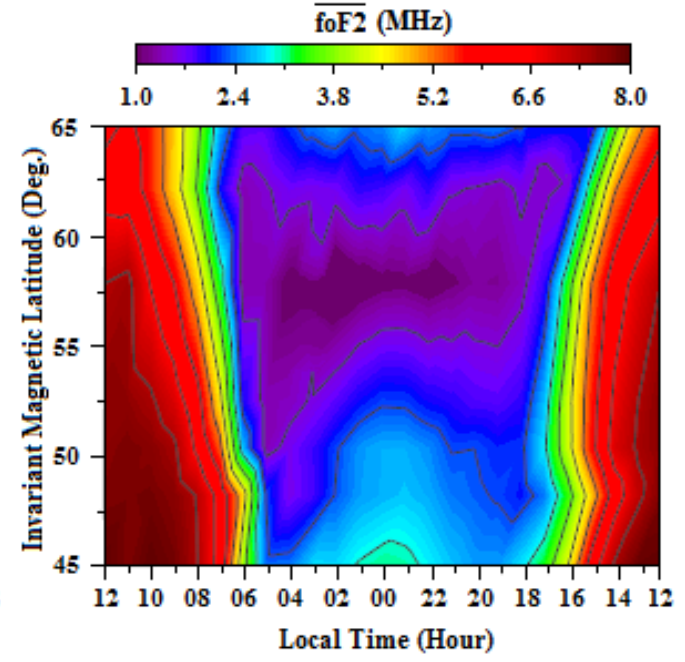

(b)

Figure 4. Variations according to invariant magnetic latitudes of the average foF2 values for different local times during 21 December Solstice period of the year 1972 (a) for geomagnetic quiet condition, (b) for geomagnetic active condition.

for March and September Equinoxes under geomagnetic quite conditions are observed between about $55^{\circ}$ $62^{\circ} \Lambda$ and for the hours between 19-05 LT. The position of the trough minimum are located at about $58^{\circ}$ $\Lambda$ for March Equinox and about $61^{\circ} \Lambda$ for September Equinox. For these seasons, the average foF2 value of the trough minimum is about $2.5 \mathrm{MHz}$. These values are observed for the hours between 03-01 LT for both March Equinox and September Equinox.

As seen in the Figure 4a, the foF 2 trough for December Solstice under geomagnetic quite conditions is observed between about $53^{\circ}-62^{\circ} \Lambda$ and for the hours between $05-18 \mathrm{LT}$. The position of the trough minimum for this season is located at about $61^{\circ} \Lambda$. The average foF 2 value of the trough minimum is about 1.3 MHz for the hours between 20-03 LT. This results show that the effect of the mid-latitude electron den- sity trough on foF2 becomes more prominent during December Solstice, but disappear during June Solstice.

Figures $1 \mathrm{~b}-4 \mathrm{~b}$ show the variations according to $\Lambda$ of the average foF 2 values for different local times under geomagnetic active conditions during March and September Equinoxes and June and December Solstices of the year 1972. As seen in the Figure 2a, not exactly determined the foF 2 trough for geomagnetic quite conditions of June Solstice is clearly observed for 01-03 LT under geomagnetic active conditions. Note that the position of the trough minimum shifts equatorward about $2^{\circ}-5^{\circ} \Lambda$ for all seasons under geomagnetic active conditions. That is, the foF 2 trough tends to occur at lower $\Lambda$ for all seasons under geomagnetic active conditions. The average foF 2 value of the trough minimum reduces about $0.3 \mathrm{MHz}$ with increasing geomagnetic activity for all seasons. In addition, the lo- 
cal time interval which the trough is observed extends with increasing geomagnetic activity for all seasons, especially for December Solstice. That is, under geomagnetic active conditions, the trough has a deeper structure and it is observed for more local times, especially for December Solstice.

Many studies were performed about mid-latitude electron density trough for different altitudes by using satellites, tomography and GPS-TEC (total electron content) since its discovery at about $550 \mathrm{~km}$ altitude in the 1960s. These studies reveal that the mid-latitude electron density trough is a persistent large-scale electron density depletion structure and it forms at the between the mid-latitude ionosphere and the high-latitude auroral. That is, the troughs are located between $40^{\circ}-70^{\circ}$ latitudes of both hemispheres for all seasons. The trough extends from dusk sector to dawn sector, so it can be seen explicitly for the nighttime hours whereas it cannot be seen clearly for the daytime hours of all seasons. The studies also show that geomagnetic activity and seasons have important effect on formation and structure of the trough. The mid-latitude electron density trough becomes prominent during the winter solstice, but weak during the summer solstice for the Northern Hemisphere. The electron density of the trough minimum reduces with increasing geomagnetic activity, so trough is more evident during the higher geomagnetic activity conditions. The trough minimum position shifts equatorward with increasing geomagnetic activity and this motion is proportional to the strength of geomagnetic activity. In addition, the local time interval which was observed the mid-latitude electron density trough expands with increasing geomagnetic activity [Muldrew 1965, Tulunay and Sayers 1971, Tulunay 1972a, Tulunay 1972b, Tulunay 1973, Tulunay 1974, Grebowsky et al. 1974, Tulunay and Grebowsky 1975a, Tulunay and Grebowsky 1975b, Grebowsky et al. 1976, Tulunay and Grebowsky 1978, Kersley et al. 1997, Tulunay et al. 1998, Rothkaehl et al. 2000, Tulunay et al. 2003, Pryse et al. 2006, Lee et al. 2011, Mikhailov and Leschinskaya 2011, He et al. 2011].

Our results agree with these results from previous studies. We find that the foF 2 trough appears between $40^{\circ}-70^{\circ} \Lambda$ for all seasons under both geomagnetic activity conditions. The foF 2 trough was not observed during the daytime hours for all seasons under both geomagnetic activity conditions, while it was explicitly observed during night hours for March and September Equinoxes and December Solstice under both geomagnetic activity conditions. We also find that the seasonal and geomagnetic activity variations have important effects on the structure of the foF 2 trough. The foF2 trough is not clearly observed during June Solstice for geomagnetic quiet conditions. Otherwise December Solstice is season to be the most effect of the foF 2 trough for both geomagnetic quiet conditions and geomagnetic activity conditions. Under geomagnetic active conditions, the minimum position of the foF 2 trough is observed at lower $\Lambda$ for all seasons. That is, the foF 2 trough tends to occur at lower $\Lambda$ for all seasons under geomagnetic active conditions. In addition, the foF2 value of the trough minimum reduces with increasing geomagnetic activity for all seasons. The local time interval which is observed the foF 2 trough extends with increasing geomagnetic activity for all seasons, especially for December Solstice. That is, the foF2 trough has a deeper structure and is observed for more local times under geomagnetic active conditions. Also the foF2 trough is clearly observed for June Solstice with increasing geomagnetic activity.

These results demonstrate that the latitudinal behavior of the electron density at the ionospheric F2 peak heights exhibit a similar structure with the latitudinal behavior of the electron density in higher regions than F2 peak. That is, the mid-latitude electron density trough has an important effect on the change of electron density in the ionospheric F2 region.

\section{Conclusions}

The results obtained from this study are presented at three main headings as follows:

(1) The different behaviors according to $\Lambda$ of average foF 2 values for the daytime hours and the nighttime hours are substantially similar to the structure of magnetosphere and plasmosphere in the nighttime hours and the daytime hours. Because the region between magnetosphere boundary and plasmosphere boundary is wider during the nighttime hours, the number of magnetic field lines decreases between $40^{\circ}$ $70^{\circ} \Lambda$. Therefore, the plasma density of this region decreases suddenly and sharply during the nighttime hours. This explains why the trough is usually observed during the nighttime hours. In addition to this, because the ionizing effect of ultraviolet and X-rays fill the trough shortly after dawn sector, the trough is not observed during the daytime hours [Tulunay 1973, Tulunay 1974, Tulunay and Grebowsky 1978].

(2) The geomagnetic activity increase caused by solar storms occur a magnetospheric electric field. This electric field occurs a drift velocity that represented by $\frac{\mathrm{ExB}}{\mathrm{B}^{2}}$. It is oriented towards to the Earth in the nighttime hours, while it is oriented outward from 
the Earth in the daytime hours. This drift velocity is one of the most important physical parameters that determine the width of the plasmosphere borders at night and day sides. Because the drift velocity under geomagnetic active hours is greater than that under geomagnetic quiet hour, it causes to more narrowing of plasmosphere border in the nighttime hours and more expansion of plasmosphere border in the daytime hours. This narrowing causes to more decrease of magnetic field lines and electron density between $40^{\circ}-70^{\circ} \Lambda$. Therefore, under the higher geomagnetic activity conditions, the troughs are more prominent and are observed more clearly for all seasons [Tulunay 1971, Tulunay 1973, Tulunay 1974, Tulunay and Grebowsky 1978].

(3) The formation and structure of trough vary depending to seasonal changes. It is determined that June Solstice is season to be least effect on foF 2 of the mid-latitude electron density trough, while December solstice is season to be the most effect on foF 2 of the mid-latitude electron density trough. This difference is a result of changing at magnetic equator position of the Earth according to Sun for different seasons and is associated with the relative positions of sub-solar point to the magnetic equator varies considerably for December Solstice [Tulunay 1971, Tulunay 1973, Tulunay 1974, Tulunay and Grebowsky 1978].

The fundamental similar behaviors between the foF2 trough and the mid-latitude electron density trough that are observed at different altitudes can be explained with the effect of diffusion created by the magnetic field gradient and drift. The results also indicate that magnetic structure called as magnetospheric plasma boundary on the mid-latitudes has a significant effect on changes of electron densities at lower altitudes. In addition to this, in order to establish a better description and prediction of the mid-latitude trough features, it is essential to combine the in situ satellite observations with those of the ground based measurements.

Acknowledgements. The authors are grateful to Prof. Dr. Yurdanur Kabasakal Tulunay for making this research possible by providing the facilities needed for the study.

\section{References}

Calvert, W. and T. E. Van Zandt (1966). Fixed-frequency observation of plasma resonances in the topside ionosphere, J. Geophys. Res., 71, 1799-1813.

Carlson, H. C. (1966). Ionospheric heating by magnetic conjugate point photoelectrons. J. Geophys.
Res., 71, 195-199.

Grebowsky, J. M., Y. K. Tulunay and A. J. Chen (1974). Temporal variations in the dawn and dusk mid-latitude trough position and plasmapause, Planet. Space Sci., 22, 1089-1099.

Grebowsky, J. M., N. C. Maynard, Y. K. Tulunay and L. J. Lanzerotti (1976). Coincident observations of ionospheric troughs and the equatorial plasmapause, Planet. Space Sci., 24, 1177-1185.

Grebowsky, J. M., N. C. Maynard and Y. K. Tulunay (1976). Coincident plasma pause-troughs observations, EOS T. Am Geophys. Un., 57:4, 299-299.

He, M., L. Liu, W. Wan and B. Zhao (2011). A study on the nighttime midlatitude ionospheric trough, J. Geophys. Res., 116, A05315, doi: 10.1029/2010JA016252.

Kelley, M. C. (1989). The Earth's Ionosphere (Plasma Physics and Electrodynamics), Academic Press, 350-354.

Kersley, L., S. E. Pryse, L. K. Walker, J. A. T. Heaton, C. N. Mitchell, M. J. Williams and C. A. Willson (1997). Imaging of electron density troughs by tomographic techniques, Radio Science, 32-4, 1607-1621.

Lee, I. T., W. Wang, J. Y. Liu, C. Y. Chen and C. H. Lin (2011). The ionospheric mid-latitude trough observed by FORMOSAT-3/COSMIC during solar minimum. J. Geophys. Res., 116, A06311, doi: 10.1029/2010JA015544.

Mikhailov, A. V. and T. Y. Leschinskaya (2011). Ionospheric altitude profiles in the main ionospheric trough as observed by field-aligned EISCAT incoherent scatter radar observations, J. Atmosph. Terr. Phys., 73, 488-498.

Muldrew, D. B. (1965). F-layer ionisation troughs deduced from Alouette data, J. Geophys. Res., 70, 2635-2650.

Pryse, S. E., L. Kersley, D. Malan and G. J. Bishop (2006). Parameterization of the main ionospheric trough in the European sector, Radio Sci., 41, RS5S14, doi: $10.1029 / 2005$ RS003364.

Rishbeth, H. and O. K. Garriott (1969). Introduction to Ionospheric Physics, Academic Press, 250-251.

Rothkaehl H., I. Stanislawska, R. Leitinger and Y. K. Tulunay (2000). Application of a trough model for telecommunication purposes, Physics and Chemistry of the Earth, 25:4, 315-318.

Sharp, G. W. (1966). Mid-latitude trough in the night ionosphere, J. Geophys. Res., 71, 1345-1356.

Tulunay, Y. K. (1972a). Some topside electron density measurements made by the Ariel 3 satellite during the geomagnetic storm of May 25-27 1967, Planet. Space Sci., 20, 1299-1307.

Tulunay, Y. K. (1972b). Magnetically symmetrical detection of the mid-latitude electron density trough by the Ariel 3 satellite, J. Atmosph. Terr. Phys., 34, 1547-1551. 
Tulunay, Y. K. (1973). Global electron density distributions from the Ariel 3 satellite at mid-latitudes during quiet magnetic periods, J. Atmosph. Terr. Phys., 35, 233-254.

Tulunay, Y. K. (1974). Mid-latitude ionosphere as observed by satellites Ariel 3 and Ariel 4, B. Am. Meteorolog. Soc., 55:6, 650-650.

Tulunay Y. K., H. Rothkaehl, G. Juchnikowski, Y. Laletas and I. Stanislawska (1998). A comparison between the Ariel 4 ambient electron density and ionospheric critical frequency over COST 251 area, Proceedings of the 2nd COST 251 Workshop, Side-Antalya, Turkey.

Tulunay, Y. K., I. Stanislawska and H. Rothkaehl (2003). Revisiting the Ariel trough work for HF telecommunication purposes, Cosmic Research Journal, 41:4, 1-13.

Tulunay, Y. K. and J. Sayers (1971). Characteristics of mid-latitude trough as determined by the electron density experiments on Ariel 3, J. Atmosph. Terr. Phys., 33, 1737-1761.

Tulunay, Y. K. and J. M. Grebowsky (1975a). Temporal variations in dawn and dusk mid-latitude trough positions, EOS T. Am. Geophys., 56:3, 172-172.

Tulunay, Y. K. and J. M. Grebowsky (1975b). Temporal variations in the dawn and dusk mid-latitude trough position-measured (Ariel 3, Ariel 4) and modeling, Ann. Geophys., 31, 29-38.

Tulunay, Y. K. and J. M. Grebowsky (1978). The noon and midnight mid-latitude trough as seen by Ariel 4, J. Atmosph. Terr. Phys., 40, 845-855.

${ }^{\star}$ Corresponding author: Erdinç Timoçin İnönü University, Faculty of Science and Art, Department of Physics, 44280 Malatya, Turkey; email: ertim44@hotmail.com.

2017 by Istituto Nazionale di Geofisica e Vulcanologia.

All rights reserved 